Debate

\title{
An argument for intolerance
}

\author{
John F Catherwood Queen's University of Belfast, Belfast
}

\begin{abstract}
"Multiculturalism", "pluralism" and "tolerance" have become buzz words in applied ethics. While serious and well thought out work is going on in these areas, a misunderstanding of the importance of tolerance, and the difficulties raised by multicultural moral conflict seems common. In this paper I argue that intolerance of some cultural traditions is morally required, and suggest that the forging of a moral mono-culture is preferable to pluralism.

(Fournal of Medical Ethics 2000;26:427-431)
\end{abstract}

Keywords: Pluralism; multicultural; tolerance; relativism

Medical practice in the UK, and across the world, faces the challenge of meeting the needs of a multicultural society. Since medicine is a science in the service of society, it is often suggested that we must respect the treatment choices that patients make in the light of their religious or cultural backgrounds. In particular, it is suggested, we must respect the moral choices made by patients in the light of their cultural or religious beliefs. Those who do not accept those choices are to be chastised and even denigrated, with terms such as "bigot" and "cultural imperialist". Of course it seems inevitable that there will be those who find it difficult to accept the actions allowed, or even demanded, by cultures other than their own. However, we should remind them that moral judgments are mere expressions of culturally influenced opinions, and that there are no right answers in a conflict of cultures, merely different ways of looking at the world. Intolerance cannot be tolerated, as the demand to achieve parity of esteem is held to warrant overriding conflicting moral opinions, and it has become a moral imperative to accept the views of others.

In discussions of medical ethics, this view is often expressed when decisions have to be made about refusal of treatment or perhaps when requests for unusual treatment are presented. Some version of the popularly revered Principle of Respect for Autonomy is usually wheeled out, along with venerable examples involving Jehovah's Witnesses or Christian Scientists. Two important features of these examples are usually stressed: that the individual practitioner's autonomy and moral judgments are not as important as those of the patient, and that the patient's opinion has this overwhelming weight because of the cultural background that forms this opinion. The Liberal tradition of autonomous freedom of the individual (for example, of the physician) is held to be an invitation to dictatorship and despotism. Patient autonomy must be respected not because the patient is an individual, but because of the position that the patient holds as part of a community: the patient's views are overriding because they are an expression of the culture that gives the patient his or her identity. Communitarianism, pluralism and multiculturalism have become the watchwords: to be moral is to accept and include the views of others in the multicultural community and hold their interests above personal moral values, even though one's values inevitably are also culturally influenced. This is not just simple majority rule. Minority views, however strange, if grounded in some cultural context must be respected by being accepted.

In contrast to the perceived arrogance of the paternalist past, a humble respect for patient autonomy has seemingly become the required norm in medical practice. Doctors who wish to avoid litigation no longer make decisions; they facilitate the informed choices of their customers. Also notable is the apologetic language and humble tone adopted by many of those who speak as professional philosophers. For most of this century those involved in academic moral philosophy have concentrated on the logic of moral utterances, and avoided the contentious world of applied ethics. Even now, with few exceptions, it is difficult to find any suggestion that philosophy might be able to give definitive answers to hard moral questions, or to find anyone who will claim moral expertise. This insecurity is perhaps understandable, for, as Alisdair MacIntyre has noted: "every modern moral philosopher is against all modern moral philosophers except himself and his immediate allies. There is scarcely any need for any external attack". ${ }^{2}$

The range of competing theories is so great, and their flaws so manifest, that it is surprising that anyone should invest any faith in any moral theory. This is especially so if one wishes to allow for differences in moral opinion that arise out of culturally differentiated views of the world. It is perhaps natural then for us to turn to moral scepticism, or at best moral relativism, and reject any notion of objective morality, or moral principles that can be universally applied. It is also natural to suggest that there can be no moral experts, except in the sense that some person may be more 
knowledgeable than others about the implications of particular cultural traditions, or the precedents for action that those traditions encompass. It is also perhaps natural to take more account of people's emotions and intuitions than much of Western analytic moral theory, with its strong rationalist leanings, might otherwise allow. The strength of people's emotional commitment to a particular principle may easily be seen as an indicator of how important that principle is in defining their cultural identity.

\section{Academic respectability}

One is left with the overall impression that if, perversely, we insist on asking ethical questions then a cautious anthropologist is likely to be the best person to provide the answers. Philosophers may of course seek to analyse problems by type, to teach our students how to differentiate between technical, factual and judgmental issues, but academic respectability demands that we avoid any hint of casuistry or moralising. The rôle of philosophers is merely to observe the claimants, and perhaps point out any invalid or fallacious reasoning, but not to judge or pronounce on the merit of any argument. They should not interfere by making critical analyses of the conceptual basis for these culturally derived requests. In particular, those who work within the tradition of analytic philosophy must not draw on that tradition and its moral theories to examine or criticise the notions derived from other cultural or religious traditions. In a toleran multicultural pluralism there is no room for individualism, and the sort of liberal or libertarian ideals that inform so much of analytic philosophica ethics. The emphasis on rights and individual freedoms, on the demand for single guiding principles, and the need for coherent universal constancy in their application are incompatible with tolerance. Analytic philosophy is "a white boy's game"3 inappropriate to a world were the vast majority of the people are non-white and/or non-male. To question the premises upon which a culturally contextsensitive judgment is based is to question that culture, and to question the identity and integrity of those who feel themselves to be part of that culture. ${ }^{4}$ Tolerance of other cultures demands that "philosophical medical ethics", if those terms mean anything at all in a multicultural context, is reduced to proof-reading by unquestioning logicians. ${ }^{5}$

Surely, the rôle of philosophy and philosophical medical ethics must amount to more than this? To one who believes that traditional behaviours (of any cultural group) can often be morally questionable, this view of how moral decisions should be made seems dangerously wrong. Without begging the question too much, I should like to draw a little on the analytic tradition and its terminology, to examine some of the basic assumptions that seem to lie behind this attempt to deny the relevance of that tradition.

There is a commonly held notion that there are no right or wrong answers in ethics. The extreme version suggests that moral scepticism is called for, that moral language signifies nothing, and moral reasoning is impossible. Less extreme versions tend to suggest subjective views of morality, where ethical judgments are merely personal opinions, possibly influenced by cultural context. The adoption of this subjective view is usually backed up by some claims about moral relativism. Since we are considering practice in a multicultural society, and it appears obvious that various cultures have different moral notions, it is suggested that this lack of agreement implies that there is no single right answer to agree about. Yet this argument is unacceptable - that we disagree about an answer does not show there is no answer. In addition, the moral relativist must assume that both cultures are putting forward different moral traditions. Unless we have already assumed moral subjectivism then this cannot be the case: it may well be that only one culture is morally justified in its traditions, and the other simply morally wrong, no matter what its opinions or cultural context.

A more sophisticated stance is that of the pluralist who claims not that there are no right and wrong answers, merely that there may be more than one right answer. Further sophistication may lead pluralists to point out that there may be many wrong answers as well. Again, the difficulty for the multicultural pluralist is that one culture's wrong answers are another culture's traditional imperatives. Simply saying that both are correct, and demanding that each show tolerance does not resolve the dispute. Moreover, it seems too hasty to assume that all or any traditional answers will be correct. To be involved in a multicultural disagreement only shows that at least one of us must be wrong. Unless good cause can be shown to accept or reject one or other view we might well argue that we should proceed with caution, because we are not sure which (if either) is correct. However, this is not a reason to say either that we should do as the pluralist suggests by abandoning debate and accepting both views, or that we should reject all moral claims as having any significance and assume moral scepticism.

\section{Practical decisions}

Of course moral scepticism may be an attractive position to take, since it is philosophically almost unassailable, but then the same is true of all sorts of scepticism, which would lead us to deny other everyday concepts about the existence of objects and other people. When practical decisions must be made such scepticism is generally rejected because it is a fruitless philosophy.

The practical demand to resolve disputes also tends to drive us away from subjectivism, or pluralism. Moral disputes arise because of the nature of moral beliefs. There is a good deal of dispute about what might count as a moral principle, but if anything is to count as one of my moral principles it surely must be true that I cannot allow others to hold and act upon contrary principles without challenge. Moral claims have a weight and importance that demand we seek to impose them 
on others. Of course, it is also generally allowed that conflicting moral claims may have different weights, even if they are culturally driven. To take an extreme example, few people, even multicultural pluralists, would argue that we should have tolerated the Thugs or the Toltecs when they expressed their cultural identity and religious faith through human sacrifice.

This is not to say that our moral theory must lead us to expect that there is only one possible good action in every case. There may be several morally acceptable courses of action in many situations (equally good or bad, equally desirable or pleasurable, equally in line with the dictates of the good will). However, these are not cases of dispute, as there are no conflicts of principle in play, and in those cases there is no reason not to respect the diversity of traditions that various cultures have evolved. A moral dispute only arises when a proposed action (traditional or novel) conflicts with the dictates of our principles, be they cultural or borne of personal subjective prescription. Resolving these cases demands that we establish which moral principle is overriding, which cultural tradition we should respect, and what is the morally correct thing to do. Whatever the right thing is, it is taken to be universally applicable no matter what culture we may be a part of. We may accept that it is difficult to find rules of justification for moral claims, but some justifications are more persuasive than others are, and the universalisability of moral judgments seems to be an important feature that cannot be abandoned.

\section{Moral expertise}

The common dismissal of the notion of mora expertise is also too abrupt. The option of moral scepticism is always open here, if someone wishes to reject the whole notion of moral justification and moral debate, but most of us think that moral questions are too important to neglect in such a fashion. More persuasive perhaps is the argument that follows on from the assumption that there are no right answers. Plainly, if any answer is as good as any other, then there is no way in which to claim to have a better answer, so expertise is impossible and there can be no moral experts. Persuasive though the logic seems, in this context the argument seems overreaching. As Frances Kamm has pointed out when talking about the rôle of philosophers on governmental commissions, the presence of unresolved disagreement does not show that there is no such thing as expertise. "[T]he fact that there is this disagreement need not reduce the sense that the commission represents expert opinion, where 'expert' means an individual who is better informed, more skilled or creative at certain ways of reasoning, etc, rather than one who has a decision procedure that yields a unique argument with which all agree."

I would be the last to think that moral philosophers are always moral people. Nor would I claim that necessarily they will be better informed and more creative, or possess some special gift for determining what physicians and others should do. Yet, even if we hold that there are no such things as infallible moral experts, there do appear to be moral incompetents in every culture, whose opinions we commonly question. I would suggest that opinions drawing on reasoned, considered, well tested arguments, based on theories honed by over two thousand years of critical analytic debate perhaps deserve more consideration than those produced by less well informed, less skilled and less creative thinkers which have not been so rigorously tested. This is not to denigrate the teachings of other equally well developed cultural traditions, where debate and reflection have similarly tested the ideals and traditions that they espouse. However, it is not always obvious that every tradition has been the subject of such reasoned questioning, no matter how old the tradition may be. One common reason for advocating tolerance of cultural diversity is that the diverse cultures have ancient roots, and that their traditions have been practised and developed over some time. Age and wisdom are not necessarily conjoined. Traditions are often born of unequal power relationships, or superstition, and it may not be acceptable to conspire with tradition to promote their continued existence.

Analytic philosophy may not give the answer, but philosophical training and familiarity with the strengths and weaknesses of various moral theories does allow one usefully to question one's own putatively moral opinions, and those of others. I see no harm in allowing those skilled in the Western analytic philosophical tradition free rein in tackling the opinions and traditions of other cultures. The debate may be refreshing for both traditions, so long as all those involved are prepared to enter into reasoned discussion.

Following from the (extremely dubious) suggestion that no culturally embedded moral opinion can be wrong, it is further argued that in such a case all opinions should carry equal weight, and each should be equally respected. Fairness requires pluralism, and tolerance is the test of our moral character. Of course to promote reasoned discussion we must act in a reasonable and tolerant fashion. We must allow those with whom we disagree to explain their position and to question ours. Nevertheless, I would strongly object to the elevation of tolerance as a moral absolute. Even if we accept that it is difficult to choose between competing moral opinions and that it may greatly offend some people to question and prohibit traditional behaviours, it seems unlikely to me that we should therefore conclude that "anything goes". If we find another person's moral opinions to be unjustified, and unacceptable, it seems more than just difficult to allow them to act in accordance with those repugnant views.

\section{Radical moral pluralism}

Despite the suggestion that we should reject the Western analytic tradition of morality, the elevation of tolerance seems to rely on some corruption of the liberal principle of respect for individual freedom. The suggestion is that we ought to allow others to 
act in ways they think morally acceptable, even if we think them morally repugnant, because they are under a similar obligation to give us the same freedom. However, I fail to see how even the most caring and respectful multiculturalist could accept this radical moral pluralism. Respecting another person's opinions, or another culture's traditions, does not always mean allowing them to act in accordance with their views, even if they are prepared to universalise their prescriptions. The libertarian principle is qualified by a clause that demands that we do not harm others, but this view of tolerance makes no such restriction. It allows us to do anything, even if it harms others, as long as we think it moral to do so under our cultural traditions.

In any case it seems unlikely that a principle of tolerance of other moral opinions can have force in moral argument. If I truly hold that something is morally wrong, can I be put under a moral obligation to tolerate it? I do not believe that I have a moral obligation to tolerate the wrong-doings of any culture that requires the murder of twins, so-called "female circumcision", involuntary euthanasia, or the ventilation of brain dead bodies to asystole without allowing the procurement of transplantable organs. No matter what religious or cultural background a person came from I would need to be convinced through strong arguments before I could accept their decision to discriminate on the grounds of race, sex or sexuality.

\section{Most dangerous}

Perhaps the most dangerous of all the assumptions that seem to underlie the current pluralism is the notion that since (supposedly) reason cannot tell us if something is right or wrong, emotion is all that we can rely upon. Outrage is elevated as a moral indicator. I would question the rejection of reason and the persuasiveness of this appeal to our emotions, especially emotions generated by cultural traditions. It is simplistic and patronising of those who talk about "other cultures" to assume that those other cultures are homogenous and unchanging. The UK, in common with most of Europe, has in the past had fine traditions of bear baiting, child prostitution and slavery. This is our cultural inheritance, but it is one that we have rejected, not merely through a sudden countrywide attack of squeamishness, but as a result of powerful moral arguments developed and sustained in the face of passionate opposition. Emotional commitment to a traditional practice does not show that the practice is right, even if the practice is seen as fundamental to the culture that endorses it. For that matter, it is also difficult to identify what can be properly called a cultural tradition, or a cultural grouping that can have traditions. A group of people may have in common a strong opinion about some long established pattern of behaviour, but it is not clear that this is enough to show that they have a separate cultural identity. Most discussions of multiculturalism tend to look towards definitions of cultural grouping that rely on language, religion and ethnic origin. This may not be enough to identify a differ- ent culture or to show that a particular view is supported by a culture. Individual cultures may have within them separate sub-cultural groups. If the existence of multicultural disagreement must be resolved by the elevation of tolerance, then why not apply this principle to sub-cultures? Currently within "my" culture (I speak, in English as a first language, as a citizen of the UK, as a white from a Judaeo-Christian background) there are groups of people who believe passionately in shooting doctors who perform abortions. Others, who also share my cultural background, believe in giving electric shocks and hormone treatments to "cure" homosexuals. Does their outrage, born of cultural and religious traditions, show that they are right? Does my disgust, show that they are wrong? I do not believe so, but my philosophical reflection convinces me that they are wrong. I also believe that as a responsible moral agent I should not be prepared to tolerate their immoral prescriptions.

The one acceptable underlying reason behind the current drive for pluralism, tolerance and communitarianism seems to be a desire to build a harmonious and stable community, and that is a laudable goal. However, I would suggest that the widely accepted simplistic pluralism, emotivism, moral relativism and moral scepticism, which I have outlined, are not likely to move us towards that goal. They inevitably lead to unresolved moral disputes, which carry with them a high emotional charge, and which we have no means of resolving. Tolerance may indeed be desirable, where morally significant matters are not involved. It is a fine thing to respect the sentiments and sense of identity evoked by following rules and customs laid down by our ancestors. Tradition plays an important part in building self image and community spirit. However, to elevate the preservation of cultural traditions to the level of a moral imperative is sentimental, in the pejorative sense of the word. It is foolish to attach so much value to the symbols of a culture, and become so concerned with the sentiments those symbols evoke, at the expense of the interests and wellbeing of both the people within that culture and those without. A community that wishes to be seen as tolerant of all the traditions that are perpetuated by the people within it, because it is good to do so, cannot also tolerate immorality in the name of those traditions. Being tolerant is only morally praiseworthy if what we tolerate is itself praiseworthy.

\section{Moral commonwealth}

At the risk of being labelled a cultural imperialist, I would like to make a plea for more intolerance. At the moment prudence, or weakness of commitment, often seem to make us willing to allow a morally repugnant practice to continue, especially if it is not in our backyard. However, if we are to be consistent and responsible moral agents then intolerance of what we reasonably argue to be immoral is required. Even if consensus in ethics is seen as desirable, consensus requires agreement, and this can only be reached through at least one side 
accepting change in its moral opinions to agree with views that previously it did not accept. The kind of pluralistic tolerance that seems so popular to preach at the moment does not demand agreemen through consensus; it promotes an agreement to differ, an agreement to allow the immoral traditions of a cultural group to be perpetuated. If a single community is to live in harmony I would suggest that a common moral and cultural basis is needed. This is not the same as calling for moral or cultural imperialism. My hope is for a moral Commonwealth, rather than an Empire. What we need is a commitment by all parties to engage in openminded debate, a willingness to engage in moral reasoning and to test our own moral opinions against those of others. We may in the end be persuaded that the opinions forged by other cultural traditions are indeed more reasonable than our own, and have to abandon our own traditions. That does not concern me. Whatever mono-culture I live in, my main concern is that it should be one that is broadly morally tolerable and not one that broadly tolerates immorality. fohn F Catherwood, MA, PhD (Belf), is Lecturer in Applied Ethics, The School of Philosophical Studies, The Queen's University of Belfast, Belfast, Northern Ireland.

\section{References and notes}

1 So pervasive is this notion that at a conference on the topic of Consensus in Bioethics the suggestion that "consensus" does not require that we must necessarily accept other people's opinions was treated with little tolerance. Indeed the distinction between consensus (which does not require toleration) and compromise (which does) seemed entirely lost on many of the participants. The conference was organised by the Centre for Professional Ethics, University of Central Lancashire, 17-18 October 1996. 2 MacIntyre A. Why is the search for the foundations of ethics so frustrating? Hastings Center Report 1979;9,4:16-22.

3 This wonderfully evocative phrase was used by Bea Campbell at the conference mentioned in reference 1.

4 Even to ask impertinent questions like "what do you mean by 'culture' or 'tradition"' might be seen as inappropriate.

5 Assuming of course that we accept what the logicians will say about entailment and proof, since their art is also the product of a long line of "dead white males".

$6 \mathrm{Kamm}$ FM. The philosopher as insider and outsider. The fournal of Medicine and Philosophy 1990;15:347-74. 